\title{
Entrevista
}

\section{AGRICULTURA DE BASE ECOLÓGICA E SUSTENTABILIDADE ENTREVISTA COM NILO SCHIAVON}

Patrícia dos Santos Pinheiro Bolsista FAPERGS-CAPES

Programa de Pós Graduação em Antropologia Social e Cultural - Arqueologia - UFPEL

\section{"Muitas vezes a gente se sente na contramão do mundo"}

Nilo Schiavon, agricultor familiar que mora na Colônia São Manoel, em Pelotas, RS, participa de uma rede já consolidada de agricultura de base ecológica que começou a se formar no início da década de 90 e que se expande por municípios vizinhos, como Canguçu, Morro Redondo, São Lourenço do Sul, Arroio do Padre e outros. A família Schiavon também com Márcia, sua esposa, e os filhos Robson, Luana e Rômulo -, que participa desde o início dessa articulação em torno da agricultura de base ecológica na região, foi uma das fundadoras da Associação dos Pequenos Agricultores Agroecologistas da Região Sul (ArpaSul), formada em setembro de 1995. Em novembro do mesmo ano, a Arpa-sul passou a realizar feiras com produtos orgânicos, que completaram 20 anos em 2015 e atualmente ocorrem em diversos locais, principalmente em Pelotas, e conta com 27 famílias ativas, além de outras em processo de entrada no grupo. Posteriormente, como parte dessa rede, foi formada a Cooperativa Sul Ecológica, que fornece alimentos para diferentes mercados institucionais (merenda escolar e Programa de Aquisição de Alimentos - PAA) e também atua em feiras em Pelotas e São Lourenço do Sul - RS. Atualmente a propriedade dessa família conta com uma experiência singular de agrofloresta, onde são ministrados cursos para um público diverso, além de pesquisas acadêmicas. 
Diante de um contexto atual pouco animador para o plantio de alimentos em geral, com mudanças no clima sentidas em sua prática cotidiana e apoio irrisório por parte do poder público para a produção familiar, Nilo alerta para uma crise alimentar em curso: "Não se plantou arroz, não se plantou feijão, a fruta também, nada. [...] Isso não é questão de um mês, é um ano, dois, três. Aquela coisa, a natureza estava se mostrando, cada ano um pouquinho. E esse ano parece que ela disse: não, agora chega. Atingiu, pelo que a gente vê, atingiu todos, pegou desde a produção de grãos, fruticultura, pegou tudo, tudo. Então onde uns não tiveram problema de vento, foi chuva demais, as águas levantaram e taparam o restante”.

Nilo traz em seu relato a experiência de se sentir "na contramão do mundo", que significou se posicionar de modo contrário ao amplo processo denominado de modernização conservadora da agricultura, que implicava em seguir preceitos e receituários que levavam à intensificação da produtividade e ao uso de alto grau de insumos externos para continuidade da produção. Esse posicionamento é marcado pela lembrança de uma grave intoxicação quando ainda utilizava agrotóxicos, situação que de modo recorrente é indicada como um marco para os agricultores que optam por uma produção sem "o químico", além do desgaste dos solos e o desequilíbrio de fauna e flora gerado por esse manejo produtivista.

Ao longo da entrevista é abordado esse processo e as implicações do uso de agrotóxicos ao longo do tempo, tanto para aqueles que fazem diretamente esse uso quanto para quem involuntariamente tem contato, seja por contaminação de solo, ar ou água, seja pelo consumo de produtos "com veneno". Essas implicações, para Nilo, estão estreitamente relacionadas com a sua escolha por produzir alimentos de base ecológica, que fez com que ele e outros agricultores dessa rede procurassem proteger suas propriedades e aproximá-las de uma "redoma”, tarefa sempre árdua. Por outro lado, sem a facilidade do agrotóxicos, outras maneiras de desenvolver a produção desafiam os agricultores a repensar seu manejo dos elementos ambientais.

Patrícia (P): Gostaria que você falasse um pouco da sua longa trajetória na Agroecologia, e também como uma liderança que está tentando fazer algo diferente dentro da configuração preponderante da agricultura.

Nilo (N): Eu sou Nilo Schiavon, eu resido na Colônia São Manoel, $8^{\circ}$ distrito de Pelotas, e a gente trabalha com produção orgânica desde 1993, quando foi todo esse processo inicial que a 
gente começou esse trabalho. E desde então a gente está na atividade, mudando muita coisa, principalmente hábitos [risos] e isso faz parte da nossa vida hoje. Dá para dizer que a gente mudou completamente a forma de viver. E isso é muito bom. Viver a vida de outra forma, a natureza de outra forma. Tudo mudou.

\section{P: Você poderia listar as produções que já foram realizadas na sua propriedade?}

N: A propriedade era da família, foi adquirida nos anos 1970, o pai comprou aquela propriedade. E desde então ela foi trabalhada com o químico. O pai não usava toda, então tinha as famílias que trabalhavam. Umas trabalhavam com leitaria, outras trabalhavam com grãos, milho, feijão, soja. E aí foi a decadência da propriedade: quando entrou a soja foi a decadência, por que as pessoas tiravam a soja, tudo que tinha de verde e ou ia para a boca do boi, que eram os animais de tração que tinham, ou senão era cortado o pasto para dar para as vacas para produzir leite. E o que sobrava era botado fogo para não estorvar, na hora de arar a terra, de limpar a terra para produzir a nova cultura. Botavam fogo para não incomodar. Aí praticamente virou um deserto. Quando a gente adquiriu essa propriedade, em 1993, a gente pegou ela totalmente degradada. E foi bem a época que eu adoeci também trabalhando com produtos químicos do pêssego, que se usava naquela época. A indústria naquela época exigia que se botasse o produto, só que não explicava que tinha que se proteger. E eu muito usei veneno para o pêssego - chamava de veneno naquela época e eu acho que é, hoje chama de remédio - trabalhando de bermuda e sem camisa, para estar aplicando o herbicida.

Então acabei adoecendo, e quando meus filhos nasceram, o Robson e a Luana, eu estava numa sala do hospital, e eles nasceram na outra. Foi em 1988. Então, a trajetória mudou muito, a forma de pensar e tudo. Como eu trabalhava com veneno, e tava no hospital por causa do veneno, e aquelas crianças nascendo, amanhã ou depois eles iam crescer e eu não tinha ideia de mudar de atividade, e eles iam me pedir um pêssego para comer e eu ia ter que dizer que não poderia dar porque eu tinha botado veneno. Então foi uma coisa que já deu aquele estalinho, né? E isso aí, depois quando surgiu essa ideia de trabalhar com produção orgânica em 1993, nós fomos uma das primeiras famílias a entrar nesse projeto, em Pelotas.

A nossa propriedade, quando a gente chegou nela, a gente teve que trabalhar com leitaria. Como todo mundo que casa não tem muito recurso, começa do zero. E a gente além 
de começar do zero, casal novo, começamos em uma propriedade morta. Foi do zero mesmo. A gente muitas vezes não tinha dinheiro nem para comprar alimentação. A gente começou a trabalhar com o leite, um ano e meio, trabalhamos com leitaria para comprar alimento para a casa. Mas isso não deu. Chegou um tempo que as vacas estavam comendo mais que nós, então vendemos as vacas e partimos para outras culturas. A propriedade quando a gente começou, pegou ela praticamente sem nada, então tudo que era insumo de matéria orgânica que a gente conseguia, palha, resíduo... Muita coisa a gente conseguiu criar dentro do açude, aguapé, transferia para a lavoura para ter um pouco de matéria orgânica, para conseguir ter algum plantio de algum produto. Com isso aí foi se evoluindo. Nunca mais se botou fogo na propriedade, e foi se usando tudo que é palha, onde a gente conseguia. O que os vizinhos não queriam, lixo, palha que os vizinhos iam tirar, a gente trazia e colocava na propriedade, com isso foi melhorando o solo.

\section{P: Tentando fazer a conexão com a configuração da agricultura na região, eu gostaria que você se situasse nessa região, incluindo a sua propriedade e os coletivos que você faz parte em relação a essa agricultura convencional e às outras formas de produção preponderantes, que tem acesso facilitado.}

N: Muitas vezes a gente se sente na contramão do mundo, por que nós temos um grupo de famílias que trabalha de uma forma limpa. Tentando minimizar ao máximo o impacto com a natureza. E tem pessoas, os nossos vizinhos, na nossa porta, fazendo o contrário. Degradando, botando veneno. Se a empresa manda botar $500 \mathrm{ml}$ por litro ou por hectare, eles botam três vezes ou ficam dobrando a dose. Isso a gente têm visto: "Se botar um pouquinho já ajuda, se botar mais vai melhorar", essa é a visão das pessoas que a gente têm como vizinhos e todos os grupos das famílias [da Arpa-sul] enfrentam essa coisa. E entra a soja, entra a área do pêssego, entra a área da fumicultura. A gente tá vivendo muito isso.

E realmente as pessoas, muitos têm falado, "Bah, Nilo, a gente consegue trabalhar no teu grupo, dá para a gente começar a trabalhar com vocês?", "Dá, não tem problema nenhum, é só tu te inserir dentro das normas da Associação e do Ministério da Agricultura que a gente tem que se adaptar, as normas brasileiras orgânicas, e aí dá, tranquilamente, pode ingressar no grupo e vamos trabalhar", "Mas o que pode botar?". Eu digo "Olha, tem os produtos próprios 
que a gente usa". "E veneno?", "Não, veneno não pode”, “Ah, então não quero”, de cara assim. É uma dependência que conseguiram formular na cabeça das pessoas: sem aquele pacote de insumos ele não vai conseguir produzir. E ele aceita, na maior, porque é fácil. É um pacotinho pronto, não precisa de receita, é só seguir o que está escrito, não precisa pensar. As pessoas hoje em dia esqueceram um pouco disso. Têm medo de pensar. Tu observar uma planta, ver o que ela está te dizendo, ver o que ela precisa, observar o solo, isso praticamente não existe mais. Tem famílias ali que sobrem num trator de manhã, araram a terra, plantaram e não botaram o pé na terra. Então, a terra é somente um suporte para a planta. Tudo o que ela precisa para viver ele tá colocando. A pessoa se dissituou. A visão, eu tenho uma visão do que é aquele $\mathrm{S}$ cortado, são duas visões diferentes, não é o mesmo valor. Duas formas de ver o dinheiro. Eu não consigo viver sem ele, agora eu não preciso acumular conta no banco. Eu preciso da minha saúde, eu preciso da minha família, eu preciso do meu pensar, do lazer e isso aí para eles não é importante.

\section{P: Sobre essa polarização ou não agricultura convencional/agricultura orgânica, no cotidiano como você vê isso?}

N: A agricultura convencional é uma agricultura que é o prático. É o fácil de fazer, é tu chegar ali e.. Só que é um produto que tu não faz para ti. Por exemplo, tu fez um coquetel de insumos para produzir uma batata, e essa batata vai para o mercado, essa batata vai para um irmão teu que está lá. Eu acho que é difícil, porque como tu vai estar dando um produto envenenado para o teu irmão? E a pessoa que tá lá na frente, queira ou não é nosso irmão. E a produção orgânica a gente tem a certeza que aquele produto que vai estar lá ele só vai fazer o bem para essa família. Para mim não tem, eu acho que a pessoa que entrou nessa linha jamais vai voltar, não tem como voltar. Eu não teria coragem de hoje chegar na propriedade e sei lá, botar um herbicida no meio do pomar. Aí eu vou sujar a propriedade, ela está tão limpinha! [risos] Porque a maioria das pessoas vê a propriedade como suja, por que tem mato em tudo, eu já acho que ela está limpa, a outra que está suja. É o inverso, são dois mundos opostos. Que bom que está tendo muita gente que está ingressando, querendo entrar nessa linha de trabalho, de várias formas, na produção, no beneficiamento, nos produtos. E outra coisa muita interessante que eu estou vendo é o retorno de pessoas acadêmicas para a agricultura. Pessoas que se formaram e hoje estão voltando pro seu pedacinho de terra, comprando seu sitiozinho. 
Isso é muito bom, vão aliar a sabedoria, o técnico com o conhecimento empírico, dos nossos antepassados, e vão botar isso em prática.

\section{P: Você chegou a ter algum problema na sua propriedade com contaminação de curso d'água?}

N: Não, na nossa propriedade não, porque quando começamos esse trabalho a gente já teve orientação de fazer justamente uma redoma entorno da propriedade, para conseguir ter o selo de produção orgânica precisa dessa redoma. Foi uma das primeiras preocupações que se teve que fazer.

Questão água, na nossa propriedade, a água de propriedades vizinhas ela passa por dentro da propriedade mas não é usada. Ela só tem o curso dentro da propriedade. A água da propriedade ela é somente de chuva ou do subsolo. Do subsolo eu não posso garantir que não venha, né, porque não tem como. Agora, que não tem contato com a água dos vizinhos, isso não tem. Mas a gente tem visto em outras propriedades exageros. Problema de descuido com vasilhame de agrotóxicos, jogados dentro da sanga, dentro dos matos. É uma coisa que não é certa, mas muito menos certo é todo aquele líquido que estava dentro daquele vidro. E eles usam demais. Tenho contato com vizinhos ali que, se é para colocar, por exemplo, 100 gramas para cada 100 litros de água, ele bota 300. E aplica sem problema nenhum.

Também a lei orgânica brasileira, no meu modo de pensar, a lei está errada, por que quem tem que provar que produz sem veneno, sem nada, é o orgânico. Quem bota veneno pode botar livre. Eu acho que isso está errado. Por exemplo, eu não posso chegar para um vizinho meu e dizer para ele: "Olha, tu tá me prejudicando". Mas a pessoa que vai trabalhar tem que transformar ela numa redoma. Tu tem que proteger por que senão há impacto e impacto grande. E quem depende de água de arroio ou coisa assim, já tem dificuldade muito grande de ter qualidade. Tu vai absorver água de um arroio que ali em cima o cara colocou herbicida. Então é um problema sério e é uma coisa que a gente brigou muito com os produtores, de cada um ter o seu açude e a sua irrigação.

A gente tem, dentro da Feira, dentro da organização, a comissão de ética, com cinco ou seis agricultores, que são fiscais, que tanto fiscaliza a si próprio quanto o seu vizinho, o seu parceiro. Foram visitadas todas as propriedades, o grupo todo, não com aquele olhar crítico, de dizer: "Olha, tu está errado, está fazendo tudo errado". Se está errado, vamos mudar, dá 
para ajeitar. Então é uma conversa. E onde teve que ser punido, é punido. É uma coisa que a gente tem como ético, então não tem como fugir, doa a quem doer.

\section{P: Em São Lourenço ouvimos o relato do Silmar ${ }^{1}$, sobre aviões que aplicam agrotóxicos, vocês também têm esse problema?}

N: Para nós não tem problema porque a área que a gente tá em contato trabalha no pêssego e o pêssego é somente pulverização baixa. No caso da soja e do arroz, aí... No caso do Silmar, ele é um prejudicado direto. No nosso caso, se entrar com uma pulverização aérea, olha, praticamente destruiria a propriedade. Se pegar uma deriva em cima da propriedade, ali praticamente a fruticultura vai toda. E aí tu imagina!

\section{P: No caso de algum agricultor orgânico ser impactado, tem a quem recorrer?}

N: A gente tem nosso pessoal técnico, que hoje no caso é o Capa que faz esse trabalho. Até agora ocorreu, há pouco dias, não com o nosso grupo, mas ocorreu com um grupo de quilombolas, que morreu 30 caixas de abelhas do pessoal, aqui perto de São Lourenço. Eu sei que eles tiveram lá monitorando direto, para ver ao certo qual o problema que houve. Remanso, a gente teve um caso também, mas não diretamente com o inseticida, mas sim o inimigo, que certamente é um inimigo natural, que quando botaram veneno na soja, matou toda lagarta. A lagarta, os inimigos naturais não tendo mais o que comer, no casa a lagarta, passaram para os ecológicos. Faz dois anos agora. Foi mais conversado com o pessoal do Capa. E a Emater Canguçu também agiu.

Mas realmente é aquilo, é fome. No momento que tu mata o alimento de um inseto, ele vai optar por outra coisa, pelo que tiver, ele não vai morrer de fome. É questão de equilíbrio. Se tu inibir um tipo de inseto, exterminar uma espécie, outra vai entrar, mais agressiva que aquela. O impacto é bem maior. Outra coisa que a gente vê é a questão do borrachudo, que na região de Canguçu tem bastante. Uma mosquinha bem pequenininha, uma preta, não é mosquito. Ela ferroa, tu nem nota, quando tu vê tem uma bolha grande e infecciona. E só atinge praticamente a nuca e os tornozelos, os dois lugares que ela pega. Ele se prolifera em água limpa e que não tenha vida, por exemplo, áreas tratadas com herbicidas,

1 Silmar Fischer mora em Santa Isabel, São Lourenço do Sul e é vizinho de grandes propriedades, em área de campo do município. 
com veneno da soja. Por que é só água limpa, sem um peixe, sem caranguejo, sem nada, então ali se prolifera, que seriam os inimigos naturais, que comeriam as larvas, a desova. Então ela não tem o inimigo natural. A região do quinto distrito de Canguçu é muito afetada por isso, lá eles têm plantação de soja.

E até uma coisa bem interessante, que no ano passado fomos fazer um passeio, fomos lá no rio Camaquã. E aquele rio, uma beleza! Muito bonito. E não achamos um lambari para contar história, em um rio daquele tamanho. É sinal de alguma coisa errada. A gente se preocupa com isso. É aquela coisa, onde tu tirar uma peça, tirar um inseto, tirar uma ave, tirar um bicho do lugar dele, vai aparecer outro. É a lógica da vida. Tira um, vai aparecer outro, diminuiu um, o outro a tendência é aumentar. Desequilíbrio, né?

Hoje a gente tem certos problemas, principalmente na fruticultura, principalmente na nossa propriedade, com a questão do passarinho, já está se tornando um problema. E como a gente tem uma grande diversidade de frutas na propriedade, então tu tem alimento praticamente o ano inteiro. Nas frutas do vizinho, tapado com veneno o ano inteiro. Então o bichinho não fica ali, ele vai só lá para casa [risos]. E eles também são seres vivos, preferem o melhor. [...] Não tem como ensacar uma área de um hectare de pêssego, é muito. A uva também. A gente tem que de alguma forma espantar, para evitar de matar. Matar não pode, então a gente espanta eles. Eles vêm de volta depois, mas...

Tem um outro impacto também na questão do ambiente. Principalmente o grande produtor de soja, pêssego (que a gente têm como vizinhos), não pode ver uma árvore de pé, derrubam tudo. É mata nativa, o que não puder cortar hoje, eles vão lá, botam fogo, descascam, amanhã ou depois passam o trator e puxam, arrancam, achando que estão limpando a terra. Está virando só produção. Eu acho que agora com a questão do CAR, isso vai ser bem interessante, porque pelo que está na lei, eles vão ter que replantar tudo o que tinha a partir de 2008. E aí eu quero ver como vai ficar. Se essa lei vai ser cumprida vai ser muito bom, só que não sei se vão cumprir.

\section{P: O que você achou desse processo decorrente do debate sobre o Código Florestal?}

$\mathbf{N}$ : Houve formas de formular a lei que não iam de acordo. Agora, do jeito que está sendo feito agora o CAR, Cadastro Ambiental Rural, eu acho que é tranquilo de fazer. A gente já está com a propriedade legalizada, já fizemos o nosso. É fácil de fazer. E outra, para quem 
tem um pouco de cuidado com o meio ambiente, não é problema nenhum, se for cumprida a lei. Agora quem está desmatando vai ter problemas. Curso d'água, eles pegam a madeira que derrubam do mato, botam dentro da sanga e botam terra em cima, no outro dia estão plantando. É o que estão fazendo. E infelizmente os órgãos públicos não dão a mínima.

\section{P: Não tem fiscalização?}

N: Tem. Eu já vim duas vezes quando eles estavam cortando e a fiscal, toda vez que eu vim, ela: "então tu espera lá, quando eles estiverem trabalhando tu vem me avisar". Eu tive que dizer para ela: "Vamos fazer o seguinte, a senhora me dá o seu salário no final do mês que eu venho". Ora, eu que acho que estou fazendo uma coisa para tentar ajudar a natureza, venho aqui, faço uma denúncia e ela ainda quer que eu traga o cara junto [risos]. Mas tem pouca fiscalização. Sei lá, eu derrubei muito mato com o pai, na época que eu era pequeno, tinha 8 , 10 anos, eu ai para o mato ajudar a cortar mato. Não se procurava recuperar a terra velha, fazia terra nova. Se precisava de uma terra melhor, ia lá e cortava uma tira de mato e fazia uma terra melhor. Só que hoje eu não consigo derrubar uma árvore mais. Tenho pena [risos]. Então mudou a mentalidade, hoje eu prefiro plantar ela do que cortar.

\section{P: Uma vez um agricultor de São Lourenço me contou que foi tentar cortar uma árvore e ela começou a chorar e ele não conseguiu mais cortá-la.}

N: E ele desistiu? [risos]. Sim, tem algumas que escorre uma seiva. Só que se tu não tiver a cabeça preparada para enxergar, tu não vai enxergar isso, tu vai meter a motosserra e cortar.

\section{P: O barulho da motosserra fica mais alto do que o do choro da árvore.}

N: Isso. Tu não nota, agora se tu está preparado para ouvir, ela não precisa nem chorar, ela só ameaça... [risos] É só ela fazer cara feia... Mas é assim que funciona. Isso é uma coisa que muda de pessoa para pessoa, tem pessoas dentro do nosso grupo que não tem tanta sensibilidade. Mas é normal, se todos fossem bem iguaizinhos, não ia ter graça.

N: São pequenas coisas que há uns anos atrás a gente não enxergava. Tem coisas que jamais eu ia passar por aquilo e ia prestar atenção. Hoje o valor daquilo ali é imenso. É diferente. 


\section{P: É um afeto, né?}

N: É, tu muda, tu muda o teu pensamento, tu muda tua forma de agir e tudo. Isso aí é bom, pelo menos para mim está sendo. [...] Eu acho que como estímulo a gente tem a dizer que o sistema de produção orgânica é um processo que não tem mais volta no Brasil. Dentro desse processo de produção orgânica tem vários aí que pode se encampar: Sistemas agroflorestais, Biodinâmica, além da Agroecologia. Então tem muita coisa hoje que tu pode pegar, pode usar, tudo isso vem a enriquecer muito mais a tua agricultura. E hoje tá muito melhor viver lá dentro da agricultura do que viver na cidade. Tu tem tudo que tu tem na cidade, tem lá. Tu tem telefone, tem televisão, tem internet. A informação que tu precisa tem na propriedade. E outra, tem que trabalhar, aqui ou lá tu tem que trabalhar, só que na agricultura tu trabalhando no que é teu. E trabalhando numa coisa que tu gosta. Eu acho que a agricultura ecológica no futuro ela vai ser muito valorizada, porque a gente está passando por crises climáticas, crises com alimentação e isso vai ser um produto que vai ser muito procurado, no mundo inteiro.

\section{P: Em relação ao desafio da produção de alimentos orgânica, ao longo do processo, tem alguma outra coisa que te fazia dar continuidade?}

N: O principal foi a questão do veneno. Depois, com a criação da Associação, da Arpa. Nós sempre trabalhamos vendendo material para indústria e a indústria ela só não mata a galinha dos ovos de ouro, mas ela deixa todos os anos sem as penas, tira tudo. E surgiu, com a criação da Arpa, a ideia de trabalhar direto com os consumidores, sem a indústria, que foi o carro chefe... Eu sempre gostei de trabalhar com o povo, e isso foi mais um atrativo, trabalhar com produtos sem veneno, evitando o intermediário, que tirava a $20 \%, 30 \%$, da tua renda.

\section{P: Pode falar mais sobre a experiência da Arpa-sul?}

N: Foi um trabalho bem árduo. 1994 já estava produzindo alguma coisa, cenoura, brócolis, couve-flor... Alguma coisa se vendia para o mercado convencional, só que aí era um produto que não tinha rosto, não tinha identidade. E no início de 1995 a gente começou com a ideia de formar grupos e trabalhar com a produção direta. Isso começou muito acanhado, com dificuldade, naquela época através das duas igrejas, a Luterana, com o Capa, e a Igreja Católica, com a Pastoral da Terra. Então foi bem difícil. Primeiro, conseguir fazer com que agricultores trabalhassem juntos, o pior problema que tinha. Depois botar na cabeça deles que 
dava para produzir sem veneno. Então naquela época fizemos vários cursos de princípios básicos da Agroecologia, aqui em Pelotas. O meu primeiro curso, que para mim abriu uma janela numa peça escura, foi o que fiz em Ipê [RS], no Centro Ecológico, lá que foi o marco principal do trabalho. E já lá a gente teve alguma coisa de experiência com o trabalho na feira da Colmeia, em Porto Alegre. Então dali já viemos com uma visão diferente de como trabalhar. A gente começou nosso trabalho em Pelotas baseado na feira da Redenção [Colmeia], em Porto Alegre, no início de tudo. E aí então dia 08 de setembro de 1995 a gente formou a Associação e no dia 19 de novembro de 1995 a gente fez a primeira feira em Pelotas.

Todo mundo se preparou para ir para a feira, saímos de casa meia noite. Eram poucos caminhões para trazer todo material, naquela época tinha 38 famílias. Viemos, foi uma dificuldade para montar a lona, ninguém sabia, mas conseguimos trabalhar, vendemos bastante produto. Na semana seguinte, viemos de novo, só que nós viemos e o consumidor não veio. Só vieram na inauguração. Não se tinha o hábito de comprar. Quando foi meio dia a gente carregou o caminhão de volta para casa, e os produtos foram todos fora. E assim sucessivamente, várias semanas. Só que no percurso a gente perdeu várias famílias. Já era difícil de produzir sem o químico, isso foi a gota d'água para saírem. Uns conseguiram retornar, e outros partiram para outra, vieram embora para a cidade. Vários pararam por não tem sucessão dentro do trabalho. E isso é uma coisa que hoje é quase o contrário. A sucessão está ocorrendo, para as famílias com orgânicos, enquanto outras famílias não é tanto. A gente está fazendo 20 anos, e quantas famílias os filhos que estudaram estão retornando para a propriedade para trabalhar o que os pais vinham trabalhando. Porque estão vendo mais retorno financeiro dentro da propriedade do que trabalhando fora.

Graças a Deus a Luana [sua filha] já está pegando essa linha. Hoje ela está em Lages, SC, em um encontro da Rede [Ecovida]. Já foi a Belém no mês passado, no Seminário de Agroecologia, então ela já tá pegando a prática. Então para ela é muito bom. Engrandece, cresce como pessoa. Até hoje eu fui na Furg, em São Lourenço, levar um pêssego, e eles estavam falando: "Bah, mas a Luana aqui não dá nem para falar com ela, por que ela está sempre além do que a gente fala para ela, ela já está sabendo lá na frente."2 [risos]. Porque ela

2 Luana cursa Licenciatura em Educação no Campo na Universidade Federal de Rio Grande (Furg). 
tem uma forma de ver a natureza que não é só de retirar, mas de cuidar dela, o que é importante para a formação de educador do campo.

\section{P: Sobre a experiência da Arpa e de outras entidades, existem várias organizações que estão apoiando. Essa nova relação de parceria, com as organizações, como se formou isso?}

N: Hoje é mais parceria, nem é apoio, já passou da parte do apoio. Hoje são parcerias que a gente cultiva, isso é muito importante. É outra visão. É não ficar na dependência, que é o projeto inicial, né? Desde que se formou a Associação, que nós éramos chamados de revolucionários, de loucos, de bagunceiros. Para conseguir as primeiras ordens para trabalhar aqui na cidade [Pelotas], a primeira feira a gente conseguiu invadindo, para conseguir ter o nosso espaço. O espaço da Dom Joaquim foi muito brigado, não queriam nos liberar a licença para trabalhar por nada. Aí tanto foi que nos disseram: "Tá bom, então vocês vão lá para o fundo da cidade". Na Dom Joaquim, naquela época não tinha nada ali, era só o tênis clube e meia dúzia de casas. Então tá, vamos para lá, “Mas só para o ano que vem”, disseram. E como nós já tínhamos data marcada, a gente disse, não é para o ano que vem, é para sábado. E fomos lá. Aí chegou fiscal de feira, um monte de gente. E a gente disse: "Não, nós vamos trabalhar, nós temos produtos". E isso aconteceu em quase todas as feiras. Na Duque de Caxias nós tivemos que invadir, por causa da burocracia da prefeitura. Na Bento Gonçalves também. Na Bento nos trocaram de lugar umas cinco, seis vezes. Não queriam deixar por nada, faziam de tudo para a gente desistir, mas estamos lá até hoje. A gente é teimoso por natureza.

Então se criou [a parceria]. Quando iniciou esse trabalho, a universidade mesmo, ela tinha vários professores que diziam que isso era besteira, que não iria dar certo. Mas iam comprar produto na feira. E no início, a Embrapa também, lá em 1998, não nos deu apoio nenhum. Hoje são nossos ótimos parceiros. Isso foi se criando, com o nosso convívio na feira. Talvez por que eles nos conheceram melhor, tanto o pessoal da universidade quanto os próprios pesquisadores da Embrapa, a gente teve mais contato com eles e se criou um vínculo, uma amizade muito grande e essa parceria, que existe até hoje e muito forte. Tem os órgãos públicos de pesquisa, a Embrapa, a Emater e as universidades, além das entidades das igrejas. 


\section{P: Retomando a questão mencionada anteriormente, você acha que há um diferencial da sucessão familiar na produção orgânica?}

N: É nas orgânicas. Por exemplo, a gente via muita mão de obra na volta, nos vizinhos, hoje em dia tu não encontra ninguém. O pessoal veio tudo para a cidade, estão ai nas vilas, passando dificuldade. Hoje dentro da propriedade a gente está pagando em torno de R $\$ 60$, $\mathrm{R} \$ 70$ reais por dia de serviço e alimentação, aqui na cidade eles trabalham talvez por $\mathrm{R} \$ 25$ reais e ainda tem que comer daquilo ali. Só que hoje eles não retornam mais. Não tem mais a propriedade, acostumaram a viver na cidade, que é diferente: aqui eles trabalham na sombra, lá tem que trabalhar no sol. Entre aspas, né? Por que lá em casa mais uns dias eu não vou mais trabalhar no sol. [risos]

Todo esse trabalho que a gente fez, com muita briga que a gente teve no início, hoje está sendo muito fácil para quem quer entrar nessa linha de trabalho. Por que todo esse processo, de briga, de dificuldade que a gente teve, essa família não vai ter mais. Toda essa caminhada que a gente fez, de dificuldade, essa dificuldade ele não vai ter. Ele vai ter sim o tempo de recuperação, o tempo do processo de recuperação do solo, que é três anos. No mínimo de três anos, e isso não tem como mudar. Agora, a partir disso, hoje ele já vai encontrar o mercado pronto, em expansão. Ele já vai entrar com o produto dele vendido. Então isso já é meio caminho andado. E o restante é confiar no que já tem muito colono antigo que está fazendo. É buscar informação, por que quando nós começamos a gente não tinha informação aqui perto, hoje tem. Eu queria ter hoje 25 anos, com a experiência que eu tenho (risos). Por isso que eu digo para as crianças: "Olha, vocês tem a faca, o queijo e a schimia na mão".

Entrevista realizada em 10 de novembro de 2015 por Patrícia dos Santos Pinheiro. 